\title{
EVAluATing Alternative SEED-COTTON RECLAIMERS FOR HIGH-SPEED ROLLER GINNING
}

\author{
C. B. Armijo, D. P. Whitelock, P. A. Funk, J. W. Thomas
}

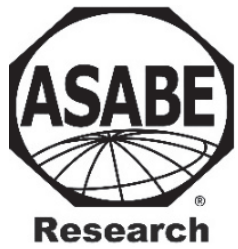

\section{HighLIGHTS}

- Experimental high-capacity seed-cotton reclaimers were evaluated for the growing high-speed roller-ginning industry.

- The experimental reclaimers minimized the amount of seed-cotton loss compared to the conventional reclaimer, but had more seed loss than a conventional reclaimer.

- The conventional reclaimer had the lowest combined seed and lint loss when processing Pima cotton.

- An experimental reclaimer based on a current cotton gin machine had seed and lint losses nearly $\$ 10$ per cotton bale less than the conventional reclaimer when processing Upland cotton.

ABSTRACT. In a roller ginnery, a reclaimer machine removes partially-ginned or unginned seed cotton (carryover) from the mixture of carryover and ginned cottonseed that is expelled from the roller-gin stand during operation and returns the carryover to the gin stand for re-ginning. Conventional seed-cotton reclaimers are marginally adequate in their capacity to handle the increased carryover that high-speed roller ginning produces. Overloading a reclaimer often leads to choke-ups and downtime for the ginnery. The objective of this study was to develop and test high-capacity reclaimers. A modified 3-saw cylinder stick machine and a modified 2-saw cylinder gin-stand feeder were tested and compared to a conventional reclaimer. The saw-cylinders in the modified machines were operated at standard full speed, 1/2 of full speed, and 3/4 of full speed. Both Pima and Upland cotton were included in this study because there is a sizable amount of roller-ginned Upland cotton. Results showed that the experimental reclaimers reclaimed more carryover than the conventional reclaimer. An effective reclaimer will 1) reclaim carryover without also capturing residual seed that will likely be removed with cotton trash when returned to the gin stand feeder (seed loss) and 2) allow seed to pass through to the seed storage while minimizing the amount of residual carryover that escapes with the seed (carryover loss). The experimental reclaimers minimized the amount of residual carryover loss, but they had more residual seed loss than the conventional reclaimer. Increasing the saw-cylinder speeds of the experimental reclaimers decreased the residual seed loss but increased the residual carryover loss. Estimates of the value of the lost seed and of the lint on the lost carryover revealed that the conventional reclaimer had the lowest combined loss of \$3.56 per bale when processing Pima cotton and the experimental 2-saw feeder with sawcylinders operating at full speed had the lowest combined loss of $\$ 6.89$ per bale when processing Upland cotton. The results suggest that losses of lint and seed may be further reduced by using a combination in series of different types of reclaimers to take advantage of each of their respective best features.

Keywords. Cotton ginning, Roller ginning, Seed-cotton reclaimer.

(2) $(1) \Theta$ The authors have paid for open access for this article. This work is licensed under a Creative Commons AttributionNonCommercial-NoDerivatives 4.0 International License https:/creative commons.org/licenses/by-nc-nd/4.0/

Submitted for review in September 2019 as manuscript number MS 13704; approved for publication as a Research Article by the Machinery Systems Community of ASABE in March 2020.

Mention of company or trade names is for description only and does not imply endorsement by the USDA. The USDA is an equal opportunity provider and employer.

The authors are Carlos B. Armijo, Textile Technologist, Derek P. Whitelock, Research Leader, Paul A. Funk, Agricultural Engineer, USDA-ARS Southwestern Cotton Ginning Research Laboratory, Mesilla Park, New Mexico; and Joe W. Thomas, Retired, Lummus Corporation, Savannah, Georgia. Corresponding author: Derek P. Whitelock, PO Box 578, Mesilla Park, NM 88047; phone: 575-526-6381; e-mail: derek.whitelock@usda.gov.

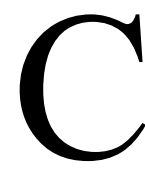

ompared to saw ginning, roller ginning is a gentler and less-damaging method of separating fiber from cottonseed and traditionally has been used to gin extra-long-staple Pima cotton (Gossypium barbadense) to retain its superior fiber properties. In a roller ginnery, a small percentage of seed cotton is not able to be ginned due to congestion at the ginning point and is removed from the ginning point along with fully ginned seed by the rotary knife. This partially-ginned or unginned seed cotton is called “carryover" (Armijo et al., 2017; fig. 1). The carryover falls with the seed onto a conveyor belt or seed belt that conveys the carryover and seed (referred to as carryover/seed from this point forward) away from the gin stand, usually collecting carryover/seed from multiple gin 


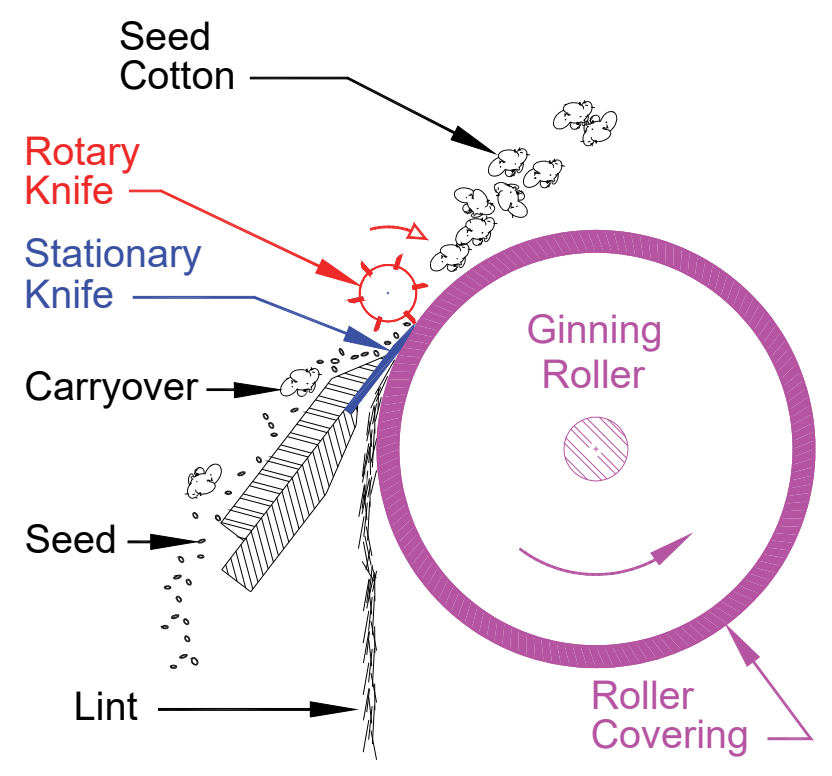

Figure 1. Diagrammatic presentation of a rotary-knife roller-gin stand.

stands along the way. To avoid financial losses from the lint attached to the carryover ending up in the seed storage pile or hopper when it should be in the cotton bale, a specialized machine is employed to reclaim the carryover and return it to the gin stand for ginning. An effective reclaimer must reclaim the carryover with minimal residual seed and minimize the residual carryover that passes through with the fully ginned seed output to the seed pile (fig. 2). Residual seed returned to the gin stand with the reclaimed carryover will likely be removed with cotton leaf, sticks, and burs (trash) at the gin-stand feeder and result in a loss of revenue. In addition, residual carryover with attached lint passing through the reclaimer with the seed output to seed storage will result in a loss of revenue due to lint in the seed rather than in the bale.

From a 2004 survey of U.S. roller gins, Whitelock et al. (2007) reported that the typical roller ginnery had 16 rotaryknife gin stands, with each 1-m (40-in.) wide stand producing approximately $218 \mathrm{~kg}(480 \mathrm{lb})$ or one bale of lint per hour (the rotary-knife gin stand is the only type of roller gin used in the U.S.). A single reclaimer usually handles carryover from six to eight gin stands. Carryover from a roller-gin stand is typically less than $6 \%$ of the seed cotton presented to the stand (Gillum, 1979). Figures 3 and 4 show diagrams of two types of conventional reclaimers, which contain saw cylinders, grid bars, and a doffing brush. The rotating saws snag the lint fibers attached to the carryover but not the

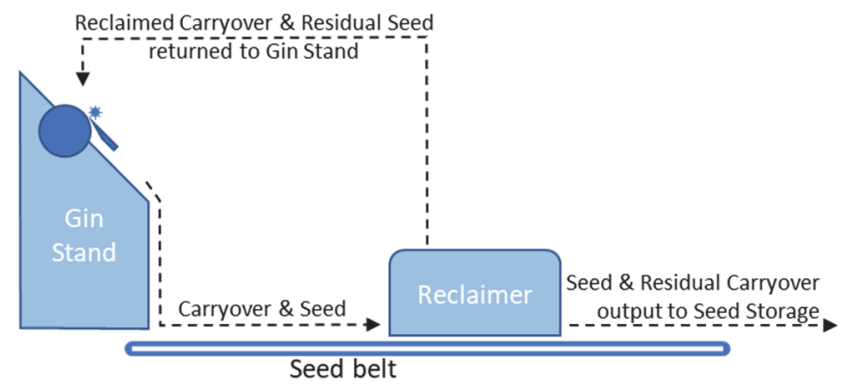

Figure 2. Diagram of seed and carryover flow at a roller ginnery.

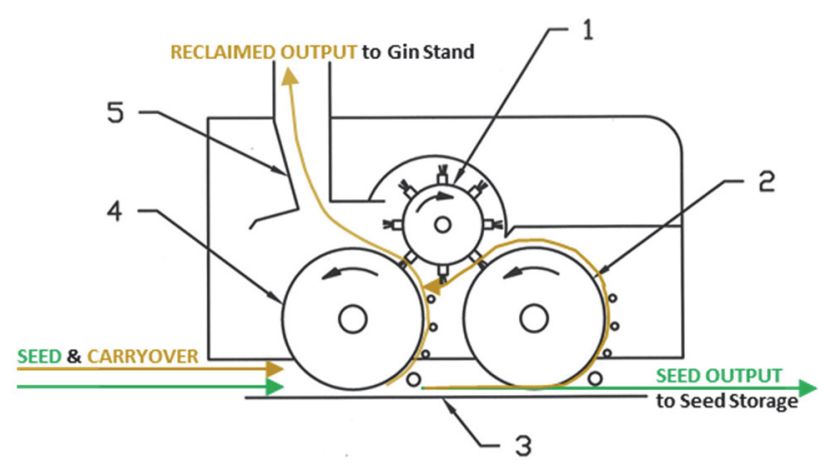

Figure 3. Cross section of Lummus Corporation reclaimer. (1) Doffing cylinder; (2) second saw cylinder; (3) seed drag belt; (4) first saw cylinder; (5) suction pickup deflector. Typical seed path in green and typical carryover path in gold (courtesy of Lummus Corporation).

ginned seed that are either on the seed belt (fig. 3) or fed directly to the reclaimer saw (fig. 4), depending on the reclaimer configuration. The carryover then passes over a series of grid bars that shake loose ginned seed still intermixed with the carryover. This seed falls through the grid bars back onto the belt (fig. 3) or to the seed outlet (fig. 4) to be conveyed to seed storage. The reclaimed carryover attached to the rotating saws is removed from the saws by the doffing brush and returned to the gin stand for processing.

At the time of the survey by Whitelock et al. (2007), the only type of gin stand used in the United States was a conventional stand that ginned about one bale per hour. This is approximately one-fifth the rate of saw ginning on a perwidth basis. Development of a higher-capacity rotary-knife roller-gin stand came into fruition about 2005 when control technologies became more advanced and affordable (Armijo

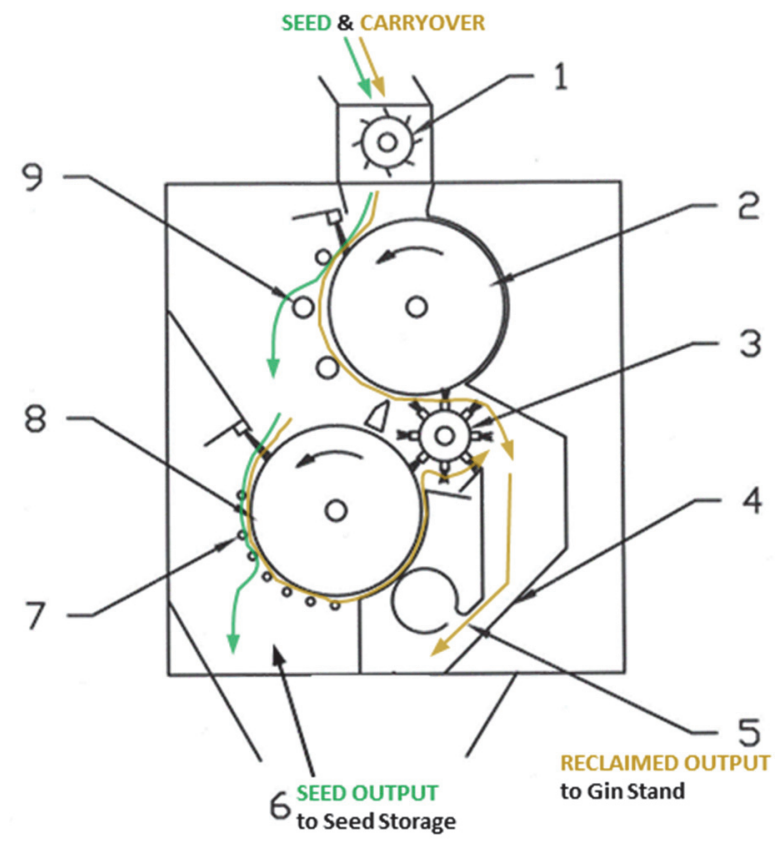

Figure 4. Cross section of a Continental Eagle reclaimer. (1) Breaker cylinder; (2) main saw cylinder; (3) doffing brush; (4) adjustable sheet; (5) reclaimed seed-cotton outlet; (6) seed outlet; (7) grid bars; (8) reclaimer saw cylinder; (9) control bars. Typical seed path in green and typical carryover path in gold (courtesy of Bajaj ConEagle Corporation). 
and Gillum, 2007, 2010; Armijo et al., 2013). A high-speed roller-gin stand is now the commercial standard. The goal of high-speed roller ginning was to make the processing rate of a roller-gin stand more in line with that of saw ginning on a per-width basis to encourage more roller ginning of Upland cotton (Gossypium hirsutum). Roller ginned Upland cotton has a fiber that is longer and more uniform and contains less short fiber and fewer neps than its saw-ginned counterpart. The high-speed stand processes Upland cotton at approximately $871 \mathrm{~kg} / \mathrm{h}$ per m $(585 \mathrm{lb} / \mathrm{h}$ per ft) of machine or about four bales per hour (Armijo and Gillum, 2007). Conventional reclaimers were designed for conventional roller ginning production rates and therefore, are marginally adequate in their capacity to handle the increased carryover that highspeed roller ginning produces. Overloading a reclaimer often leads to choke-ups and downtime for the ginnery. Also, when ginning Upland cotton, conventional reclaimers tended to allow an excessive amount of fiber to pass along with the seed.

Recent work to improve roller-gin reclaimer systems was conducted at the USDA-ARS Southwestern Cotton Ginning Research Laboratory (Hughs, 2009). An initial prototype was based on a cotton gin impact cleaner, which is a standard seed-cotton cleaning machine used in the ginnery to clean leaves and small trash from seed cotton before ginning (Baker et al., 1994). Testing and high-speed photography revealed unsatisfactory separation of seed from the carryover. A second design was based on the concept of an extractor 2-saw cylinder stick machine, which is another standard machine used in the pre-cleaning section of a ginnery to extract sticks and burs (Baker et al., 1994). The stick machine uses the centrifugal force of cylinders rotating at high-speed to extract trash from seed cotton. When used as a reclaimer, ginned seed would be separated from carryover. A unit-type prototype reclaimer was built and tested. The reclaimer was $1.0 \mathrm{~m}$ (40 in.) wide, the same width as a gin stand, and bolted directly to the front of the gin stand. It consisted of two $229-\mathrm{mm}(9.0-\mathrm{in}$.) diameter saw cylinders, and one $178-\mathrm{mm}$ (7.0-in.) doffing brush situated between the saw cylinders. The drives were operated with variable frequency drive controllers. Carryover/seed from the gin stand was fed to the first saw cylinder and placed onto the saw teeth by a stationary brush. The seed was slung off the saw cylinder by centrifugal force and collected in a separate container. Round 9.53-mm (0.375-in.) diameter grid bars spaced $25.4 \mathrm{~mm}$ (1.0 in.) apart were located around the periphery of the saw cylinders to help control the loss of carryover and aid in removing seed. The gap between the grid bars needed to be large enough to allow seed to be slung off. The doffing brush removed the carryover from the saw cylinder to be returned to the gin stand for further ginning. Separation of ginned seed and carryover occurred in the same manner with the second saw cylinder. Several trials and modifications were performed on the prototype. Results showed that the reclaimer had more than enough capacity (Hughs et al., 2015). However, it had an unacceptable amount of residual seed in the reclaimed output, probably due to the small size and high surface speed of the saw cylinders.

The current effort focused on two devices: a reclaimer based on a Continental/Moss-Gordin Little David 3-saw cylinder stick machine (Bajaj ConEagle LLC, Millbrook, Ala.) and a standard Lummus Model 700 III gin-stand feeder (Lummus Corporation, Savannah, Ga.). The objective of this study was to test the modified 3-saw cylinder stick machine and modified Model 700 gin stand extractor-feeder for use as high-capacity seed-cotton reclaimers with a conventional reclaimer included as a control in the test.

\section{EQUIPMENT SETUP}

The reclaimers were tested at the USDA-ARS Southwestern Cotton Ginning Research Laboratory (SWCGRL) in Las Cruces, New Mexico. A Hardwicke-Etter reclaimer with similar configuration to the reclaimer in figure 3 installed in the roller gin at the SWCGRL was used as the control conventional reclaimer. Figure 5 shows the actual unit installed over the seed belt at the SWCGRL. The reclaimer has two saw cylinders and one doffing brush. Each saw cylinder contains 13 saws that are $304.8 \mathrm{~mm}$ (12 in.) in diameter and spaced 15.88 $\mathrm{mm}(0.625 \mathrm{in}$.) apart. Each saw has four grid bars around the periphery. The clearance between each grid bar and the saw is $9.525 \mathrm{~mm}(0.375 \mathrm{in}$.). The bottom grid bar is $21.43 \mathrm{~mm}$ ( 0.84375 in.) in diameter. The other three gird bars are 9.525 $\mathrm{mm}(0.375 \mathrm{in}$.) in diameter. The grid bars are spaced $50.8 \mathrm{~mm}$ (2.0 in.) apart from each other. The doffing brush is $160 \mathrm{~mm}$ (6.313 in.) in diameter and contains eight brushes spaced evenly apart around the circumference of the brush.
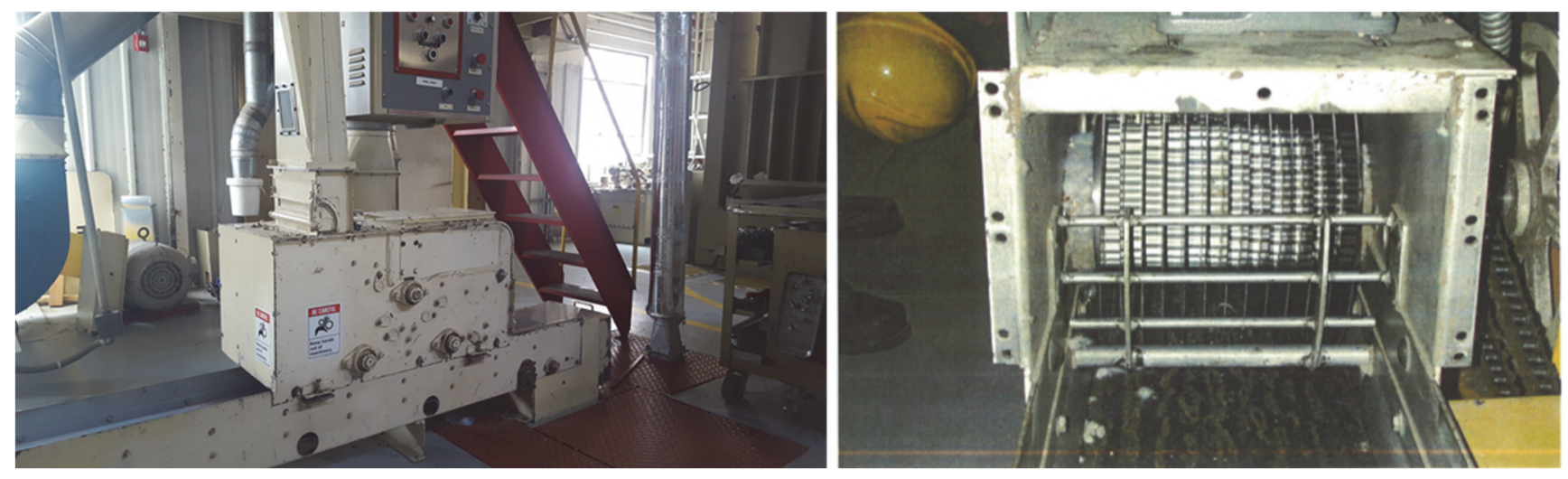

Figure 5. Hardwicke-Etter reclaimer installed over the roller-gin seed belt at the USDA-ARS Southwestern Cotton Ginning Research Laboratory (left) and with saws and grid bars exposed (right). 


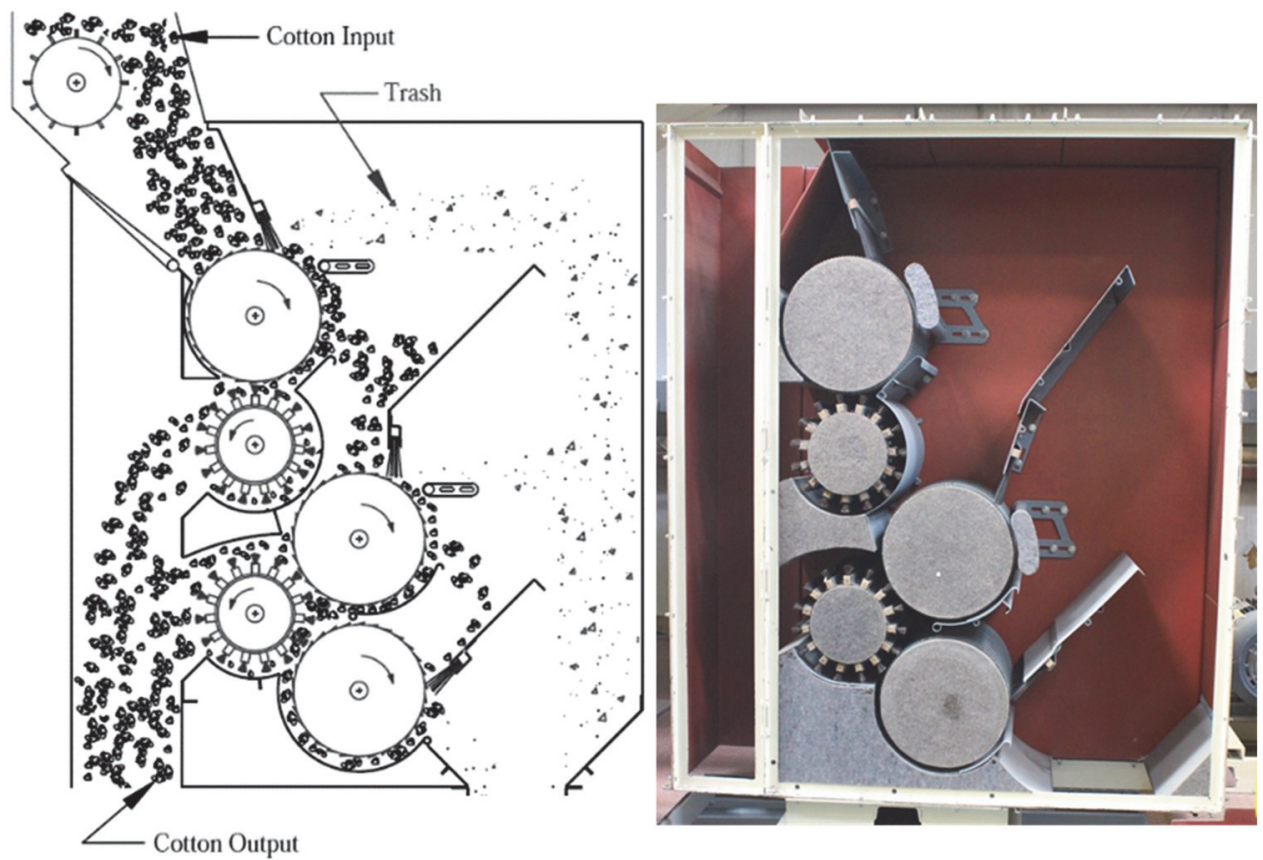

Figure 6. Diagram and photograph of a 3-saw cylinder stick machine (not modified).

Figure 6 shows the 3 -saw cylinder stick machine used in the test in its stock configuration (no modifications). This stick machine is a gravity-fed, Continental/Moss-Gordin Little David, with two 0.349-m (13.75-in.) diameter channeltype (sling off) cleaning saw cylinders and one channel-type reclaimer saw cylinder. Two round 25.4-mm (1.0-in.) diameter grid bars, spaced $69.9 \mathrm{~mm}$ (2.75 in.) apart, are set next to each cleaning cylinder. There are two doffing brushes that measure $305 \mathrm{~mm}$ (12 in.) in diameter and contain 15 sticktype brushes each. The standard stick machine is $1.8 \mathrm{~m}$ (72 in.) wide and rated at 3.3 to 6.6 bales/h per $\mathrm{m}(1.0$ to $2.0 \mathrm{bales} / \mathrm{h}$ per $\mathrm{ft}$ ) of width.
The modified 3-saw cylinder stick machine used in the test was cut-down to $406 \mathrm{~mm}$ (16 in.) wide to use in a smallscale laboratory ginnery and has a clear Lexan side for viewing. It contains the same sized saw cylinders, doffing brushes, and grid bars as the full-sized model. Figure 7 shows a diagram and a photograph of the actual machine used in the test. The modifications to the machine included removing the scrolls underneath the two cleaning saw cylinders to give seed an exit point, adding a wedge behind the top doffing brush that extended to the centerline of the second cleaning saw cylinder to direct seed to the rear part of

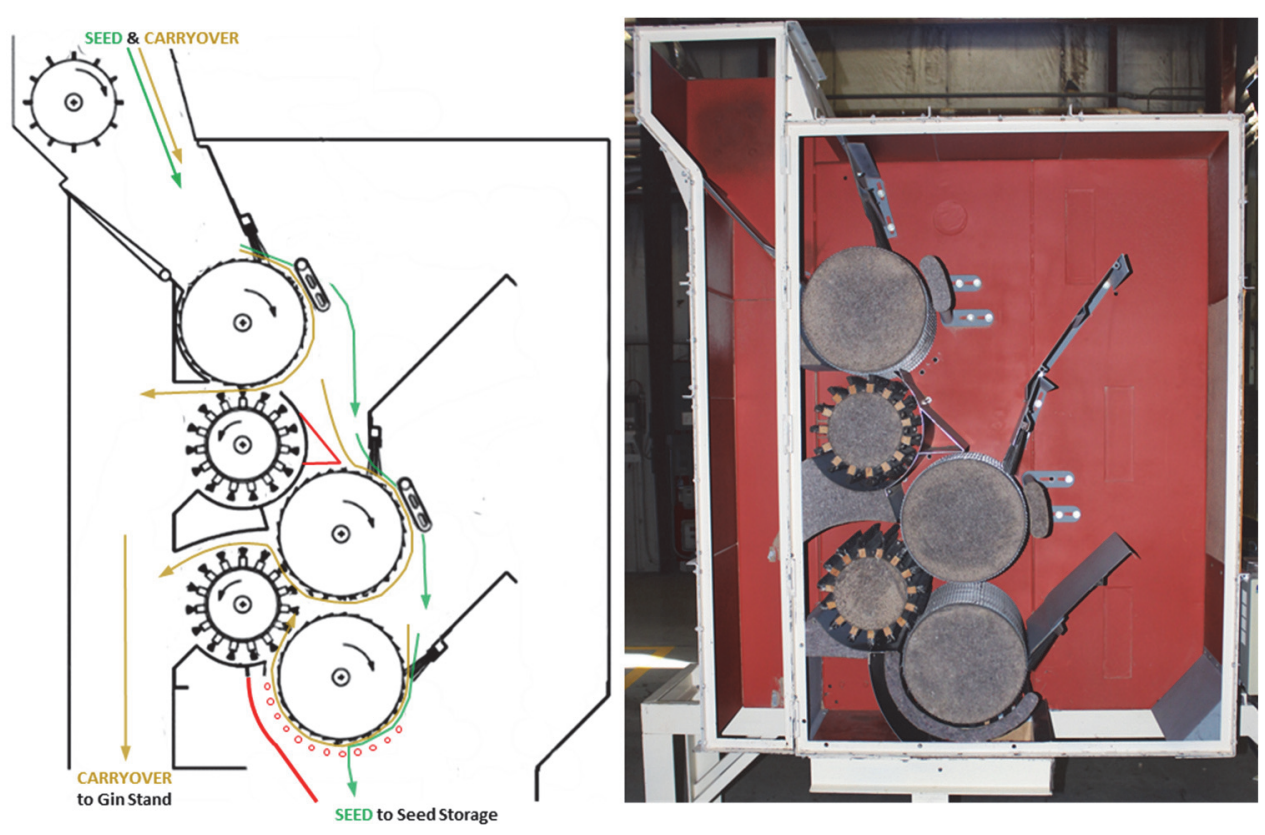

Figure 7. Diagram and photograph of the 3-saw cylinder stick machine with modifications used in the test. Added structures indicated in red. Typical seed path in green and typical carryover path in gold. 
the cylinder, and replacing the scroll underneath the reclaiming (bottom) saw cylinder with 12 grid bars spaced $25.4 \mathrm{~mm}$ ( 1 in.) apart to allow seed to more easily fall out during operation.

Figure 8 is a diagram of a conventional Lummus Model $700 \mathrm{III}$ feeder (no modifications). The current feeder is sold as either 2.44 or $3.05 \mathrm{~m}$ (96 or $120 \mathrm{in}$.) wide, but earlier versions were $1.68 \mathrm{~m}$ (66 in.). A top row of four spiked cleaning cylinders over screen grids open up the seed-cotton locks and remove fine trash. The seed cotton is then directed to the bottom section that contains two channel-type saw cylinders and one doffing brush. The top cylinder is a cleaning cylinder and the bottom cylinder is considered a reclaiming cylinder. Both cylinders have round grid bars spaced $12.7 \mathrm{~mm}$ ( 0.50 in.) from the saw surface around their periphery. The five grid bars on the cleaning cylinder are $25.4 \mathrm{~mm}$ (1.0 in.) in diameter and are spaced $95.3 \mathrm{~mm}$ (3.75 in.) apart. The top three grid bars on reclaiming cylinder are $25.4 \mathrm{~mm}$ (1.0 in.) in diameter and are spaced $42.9 \mathrm{~mm}$ (1.688 in.) apart. The remaining 14 grid bars on the reclaiming cylinder measure $19.1 \mathrm{~mm}(0.75 \mathrm{in}$.) in diameter and are spaced $30.2 \mathrm{~mm}$ (1.1875 in.) apart. Both saw cylinders are doffed by a common brush cylinder. The saw cylinders and doffing brush measure 457 and $445 \mathrm{~mm}$ (18 and $17.5 \mathrm{in}$.) in diameter, respectively.

The Model 700 feeder used in the test was cut down to $305 \mathrm{~mm}$ (12 in.) wide for use in a small-scale laboratory ginnery and had a clear Lexan side for viewing of the process. It contained the same size saw cylinders and doffing brush as the full-size model. Figure 9 is a photograph of the actual machine used in the test. The only modification done to the 700 feeder used in the test was to bypass the top row of inclined cleaning cylinders due to ginned seed becoming lodged between the spikes and screen. A hopper was installed to place carryover directly on the first (top) saw-cylinder.

These experimental machines were cut down or narrower than their commercial ginnery counterparts for research use

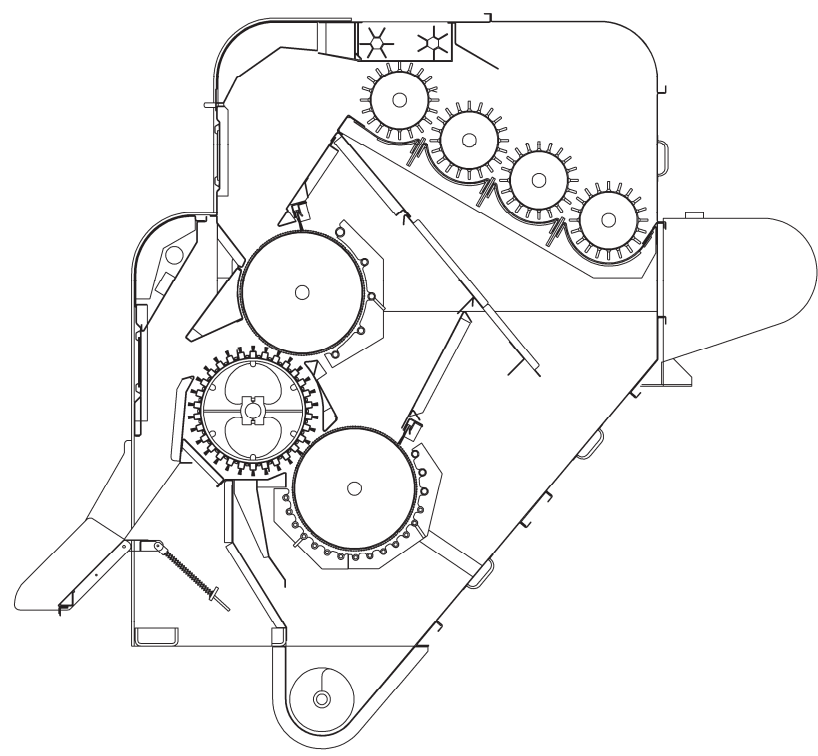

Figure 8. Diagram of Lummus Model 700 III feeder used in the test (top row of inclined cleaning cylinders was bypassed).

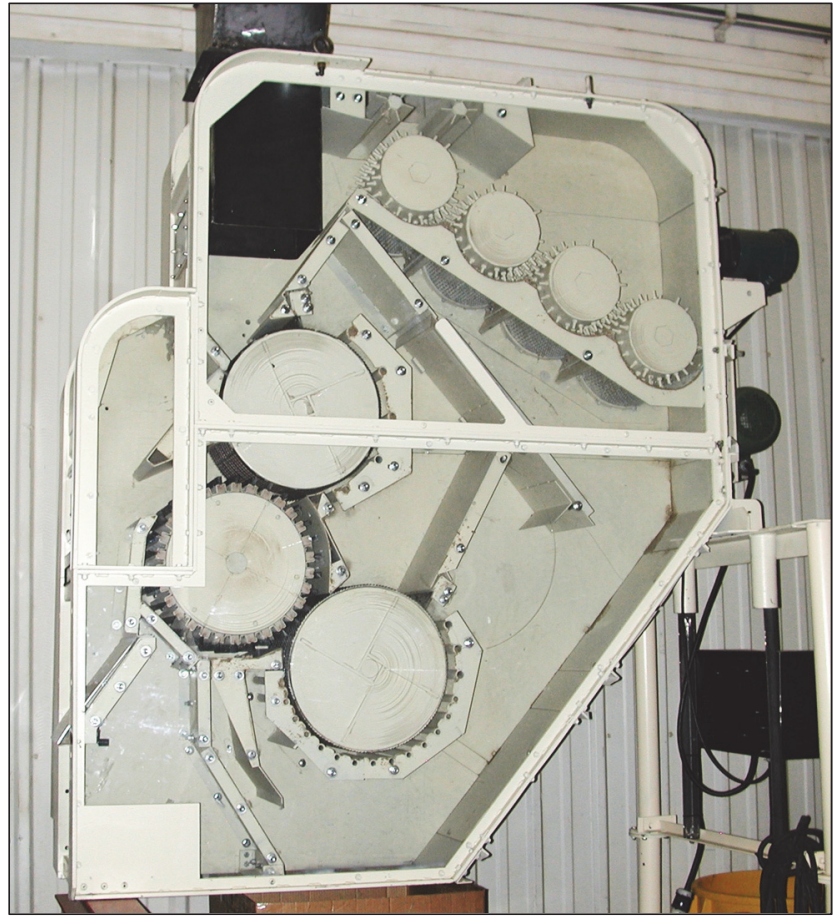

Figure 9. Modified Model 700 feeder used in the test.

in a laboratory ginnery. Anthony and McCaskill (1974) performed a study comparing narrow- and full-width ginning equipment and found no difference in total foreign matter content in the seed-cotton processing subsystem. They concluded that the use of narrow equipment as a research tool does not introduce systematic errors.

\section{Experimental Procedures}

The test consisted of two types of cotton, seven reclaimer treatments, and three replications for a total of 42 lots. The reclaimer treatments consisted of the following: 1) conventional, 2) modified 3-saw cylinder stick machine (3saw) running at $1 / 2$ of full speed (3saw-1/2), 3) modified stick machine running at $3 / 4$ of full speed (3saw-3/4), 4) modified stick machine running at full speed (3saw-Full), 5) modified Model 700 feeder (700) running at $1 / 2$ of full speed $(700-1 / 2), 6)$ modified Model 700 feeder running at $3 / 4$ of full speed (700-3/4), and 7) modified Model 700 feeder running at full speed (700-Full). Table 1 shows the measured saw speeds for the reclaimer treatments.

The cottons included Dyna-Gro 3385 Upland (DG 3385, picker harvested in Las Cruces, N. Mex.; Dyna-Gro Seed, Geneseo, Ill.) and Deltapine 340 Pima (DP 340, picker harvested in Las Cruces, N. Mex.; Monsanto Company, St.

Table 1. Saw speeds for reclaimer treatments.

\begin{tabular}{lccc}
\hline \multicolumn{1}{c}{ Treatment } & $\begin{array}{c}\text { First or Top Saw } \\
\text { (Speed, rpm) }\end{array}$ & $\begin{array}{c}\text { Second or Middle Saw } \\
\text { (Speed, rpm) }\end{array}$ & $\begin{array}{c}\text { Bottom Saw } \\
\text { (Speed, rpm) }\end{array}$ \\
\hline Conventional & 205 & 205 & - na- \\
3saw-1/2 & 196 & 149 & 92 \\
3saw-3/4 & 296 & 224 & 139 \\
3saw-Full & 395 & 299 & 186 \\
700-1/2 & 231 & -na- & 231 \\
700-3/4 & 347 & -na- & 347 \\
700-Full & 464 & -na- & 464 \\
\hline
\end{tabular}


Louis, Mo.). The study included Pima and Upland seed cotton since much of the California Acala crop is roller ginned with both conventional and high-speed stands and sold directly to the spinning mill on a contract basis for special use. Producers realize an extra premium of 13 to $26 \notin / \mathrm{kg}$ (6 to $12 \notin / 1 b)$ for the Upland cotton. Some of this cotton is of sufficient quality that mills are able to blend it with Pima cotton. Because both cotton types are being roller ginned, it was of interest to know how they interact with the reclaimer treatments.

For each lot, $45.4 \mathrm{~kg}(100 \mathrm{lb})$ of seed cotton was precleaned and ginned on a 1.0-m (40-in.) wide Lummus highspeed roller-gin stand. Pre-cleaning included two 6-cylinder incline cleaners, one stick machine, and, since seed-cotton moisture content was 5-6\% w.b., no drying. All of the carryover/seed removed by rotary knife from the gin stand ginning point was collected in a container. This represents the material that a reclaimer would be presented with. From each $45.4 \mathrm{~kg}$ (100 lb) of seed cotton, 28 to $29 \mathrm{~kg}$ (62 to $64 \mathrm{lb}$ ) of carryover/seed was collected.

To prevent contaminating the pre-cleaning and ginning systems between cottons, the test was run by cotton type. The test order was blocked by replication and the reclaimer treatments were randomized within replication. Statistical analyses were conducted using JMP (ver. 12.2.0, SAS Institute, Inc., Cary, N.C.). The Fit Model platform with the standard least squares option was used to fit a mixed model with the reclaimer treatment as the main effect and reclaimer treatment nested within replication as a random effect. The recommended restricted maximum likelihood (REML) method option was selected for fitting the mixed models.
Multiple-pairwise comparisons of the least square means were performed using Tukey HSD.

Sampling included two subsamples of approximately $0.30 \mathrm{~kg}(0.66 \mathrm{lb})$ of seed cotton after pre-cleaning to determine foreign matter content at ginning. Approximately $60 \mathrm{~g}$ (2.1 oz.) each of seed cotton and carryover/seed were collected to determine moisture content prior to ginning and reclaimer testing, respectively. Foreign matter and moisture contents of the seed cotton and carryover/seed samples were determined using standard SWCGRL procedures based on Shepherd (1972) and Funk et al. (2018).

The reclaimer testing proceeded as follows. The $45.4 \mathrm{~kg}$ $(100 \mathrm{lb})$ seed-cotton lot was fed to the gin stand and ginned at an average rate of $4.1 \mathrm{bales} / \mathrm{h}$ for the Pima and $2.9 \mathrm{bales} / \mathrm{h}$ for the Upland. The carryover/seed from the gin stand ranged from about 28 to $29 \mathrm{~kg}$ (62 to $64 \mathrm{lb}$ ) and was removed from the conveyor belt with a suction nozzle and collected in a container. The carryover/seed was then placed on a variable speed conveyor (fig. 10) and fed to the reclaimers at a rate to match the rate per unit width at which it was collected from the seed belt during ginning. The reclaimers separated the carryover/seed into two portions: seed output and reclaimed carryover, which were collected separately. At this point in a ginnery, the seed output would be sent to the seed storage pile or hopper, and the reclaimed output would be returned to the gin stand for re-ginning.

As stated earlier, the ideal reclaimer will reclaim carryover to return to the gin stand that is free of residual seed and not allow residual carryover to pass with the fully ginned seed output to seed storage (fig. 2). There are two types of losses associated with reclaimers: 1) residual ginned seed reclaimed with the carryover in the reclaimed output that is
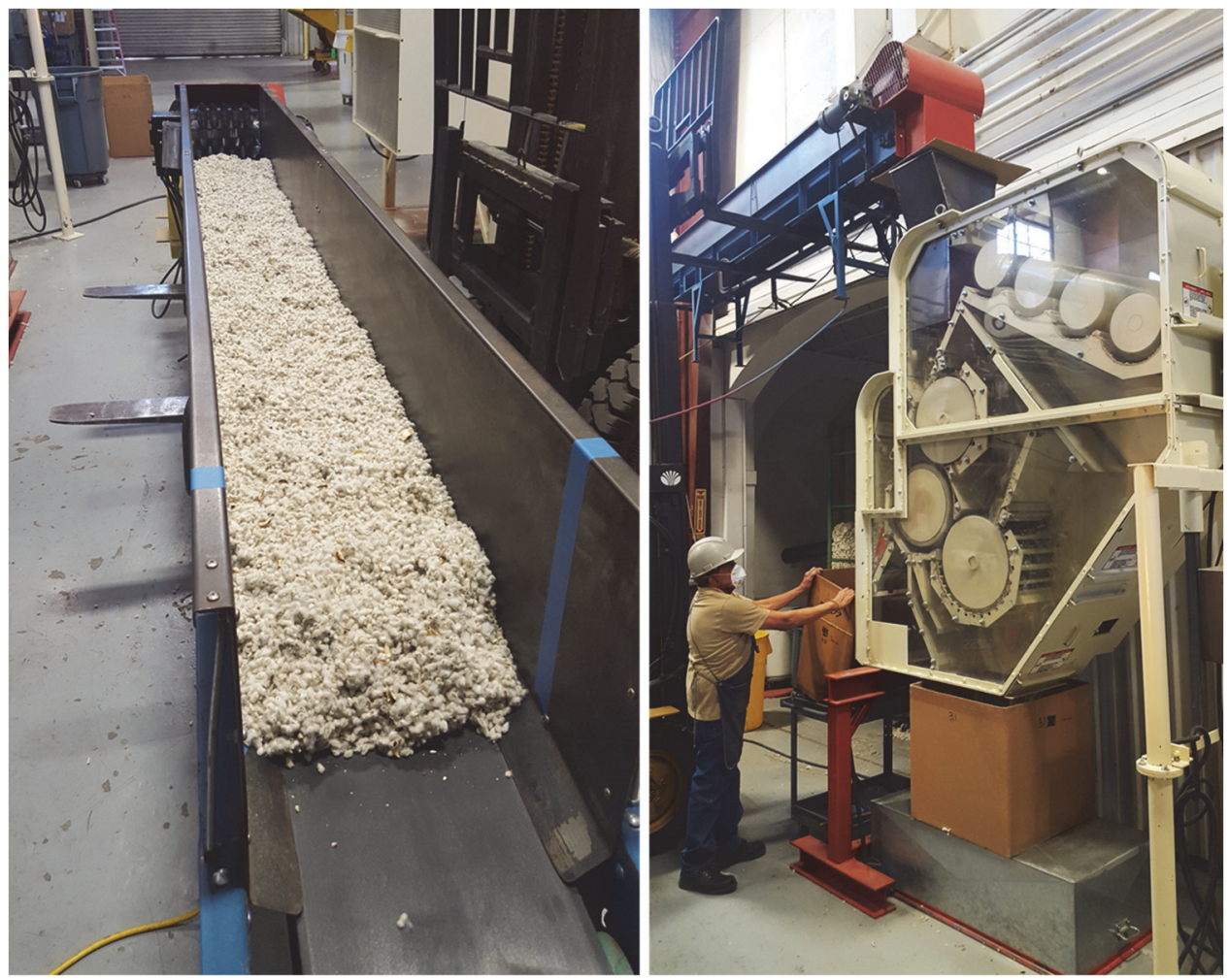

Figure 10. Conveyor belt with carryover and seed for feeding experimental reclaimers. 
returned to the gin stand and removed with trash by gin-stand feeders, and 2) lint attached to residual carryover that passes through the reclaimer with the seed output to the seed storage and does not go to the bale. To evaluate the reclaimer performance, each of the portions produced by the reclaimer (seed output to seed storage and reclaimed output returned to the gin stand) were fed individually to the modified 3-saw cylinder stick machine running at $1 / 2$ of full speed to again separate them into two fractions: ginned seed and partially or unginned seed cotton. This was repeated twice for each fraction to determine the amount of residual carryover that remained in the original seed output and to determine the amount of residual seed that remained in the original reclaimed output. These residuals were considered losses. Previous trials showed that, while complete separation was not achievable, the modified 3-saw cylinder stick machine running at $1 / 2$ speed was well suited for this procedure. Finally, the residual carryover retrieved from the seed output was ginned on 10-saw table-top saw gin to determine the amount and value of residual lint that remained on the residual carryover lost with the seed.

The value of the seed and lint loss was estimated from data for cottonseed prices and lint prices for the last five years. Upland lint price of $\$ 1.54 / \mathrm{kg}(\$ 0.70 / \mathrm{lb})$ and Pima lint price of $\$ 3.17 / \mathrm{kg}(\$ 1.44 / \mathrm{lb})$ were the average of the marketing-year quotations from 2013-2017 (USDA-ERS, 2018). The average Upland and Pima cottonseed prices used were $\$ 330 /$ t (\$300/ton) and \$320/t (\$290/ton), respectively (Informa Economics, 2013-2017).

\section{RESULTS}

Table 2 shows the foreign matter content and moisture content of the seed cotton at the gin stand, carryover moisture content at the feed conveyor, and reclaimer feed rate for the reclaimer treatments. For the Pima cotton, seed-cotton

Table 2. Treatment means and statistical analysis of seed-cotton foreign matter at gin stand, seed-cotton and carryover/seed moisture content, and reclaimer feed rate by cultivar.

\begin{tabular}{|c|c|c|c|c|c|}
\hline \multirow[b]{2}{*}{$\begin{array}{c}\text { Cotton } \\
\text { Treatment }\end{array}$} & \multirow{2}{*}{$\begin{array}{c}\text { Seed } \\
\text { Cotton } \\
\text { Foreign } \\
\text { Matter } \\
\% \\
\end{array}$} & \multirow{2}{*}{$\begin{array}{c}\text { Seed } \\
\text { Cotton } \\
\text { Moisture } \\
\text { Content } \\
\% \text { w.b. }\end{array}$} & \multirow{2}{*}{$\begin{array}{c}\text { Carryover/ } \\
\text { seed } \\
\text { Moisture } \\
\text { Content } \\
\text { \% w.b. }\end{array}$} & \multicolumn{2}{|c|}{$\begin{array}{l}\text { Reclaimer Feed } \\
\text { Rate per } \\
\text { Machine Width }\end{array}$} \\
\hline & & & & $\begin{array}{c}\mathrm{kg} / \mathrm{h} \\
\text { per m }\end{array}$ & $\begin{array}{c}\mathrm{lb} / \mathrm{h} \\
\text { per } \mathrm{ft}\end{array}$ \\
\hline Pima & 3.65 & 5.44 & 5.62 & 95.13 & 63.93 \\
\hline p-value & 0.7397 & 0.9548 & 0.9465 & \multicolumn{2}{|c|}{0.5138} \\
\hline Conventional & 3.58 & 5.39 & 5.60 & 95.31 & 64.05 \\
\hline 3 saw-1/2 & 3.69 & 5.55 & 5.61 & 94.98 & 63.82 \\
\hline 3 saw-3/4 & 3.10 & 5.29 & 5.62 & 94.87 & 63.75 \\
\hline 3saw-Full & 3.91 & 5.32 & 5.53 & 94.66 & 63.61 \\
\hline $700-1 / 2$ & 4.01 & 5.45 & 5.64 & 95.56 & 64.22 \\
\hline $700-3 / 4$ & 3.69 & 5.47 & 5.75 & 95.08 & 63.89 \\
\hline 700-Full & 3.58 & 5.59 & 5.63 & 95.45 & 64.14 \\
\hline Upland & 3.73 & 6.14 & 6.38 & 68.90 & 46.30 \\
\hline $\mathrm{p}$-value & 0.804 & 0.9923 & 0.989 & \multicolumn{2}{|c|}{0.0884} \\
\hline Conventional & 3.64 & 6.14 & 6.42 & 69.02 & 46.38 \\
\hline 3 saw-1/2 & 3.50 & 6.12 & 6.25 & 68.55 & 46.06 \\
\hline 3 saw-3/4 & 3.59 & 6.32 & 6.49 & 68.77 & 46.22 \\
\hline 3saw-Full & 3.98 & 6.12 & 6.31 & 68.81 & 46.24 \\
\hline $700-1 / 2$ & 3.65 & 6.13 & 6.34 & 69.07 & 46.42 \\
\hline $700-3 / 4$ & 3.94 & 6.10 & 6.36 & 69.11 & 46.44 \\
\hline 700-Full & 3.82 & 6.06 & 6.50 & 68.99 & 46.36 \\
\hline
\end{tabular}

foreign matter averaged 3.65\%, seed-cotton moisture content averaged 5.44\% w.b., carryover/seed moisture content averaged $5.62 \%$ w.b., and reclaimer feed rate averaged $95.13 \mathrm{~kg} / \mathrm{h}$ per $\mathrm{m}(63.93 \mathrm{lb} / \mathrm{h}$ per fit $)$. The average seed-cotton foreign matter, seed-cotton moisture content, carryover/seed moisture content, or reclaimer feed rate for the Upland cotton were $3.73 \%, 6.14 \%$ w.b., $6.38 \%$ w.b., and $68.90 \mathrm{~kg} / \mathrm{h}$ per m $(46.30 \mathrm{lb} / \mathrm{h}$ per $\mathrm{ft})$, respectively. There were no significant differences in seed-cotton foreign matter, seed-cotton moisture content, carryover moisture content, or reclaimer feed rate among the treatments for either cotton.

As mentioned earlier, reclaimers separate the carryover/seed cleared from the ginning point by the roller-gin rotary knife into two streams: seed output that goes to the seed storage pile or hopper and reclaimed output that is conveyed back to the gin-stand feeder for reginning (fig. 2). Figure 11 shows the portions of the Pima carryover/seed separated into seed output and reclaimed output by the reclaimer treatments. The conventional reclaimer separated the most (96.31\%) seed output from the Pima cotton carryover/seed, while the 3 saw at $1 / 2$ speed reclaimed the most $(9.79 \%)$ reclaimed output from the carryover/seed. Generally, the ratio of seed output to reclaimed output for the 3 saw and 700 reclaimers increased as the reclaimer speed increased. Similarly, figure 12 shows that the conventional reclaimer separated the most $(81.05 \%)$ seed output from the Upland cotton carryover/seed, while the 3 saw at $1 / 2$ speed reclaimed the most $(43.40 \%)$ reclaimed output from the carryover/seed and the ratio of seed output to reclaimed output increased as the reclaimer speed increased. For all reclaimers, a larger portion of the carryover/seed was reclaimed output when Upland was processed compared to when Pima was processed, which was expected since Upland cotton has a stronger fiber-to-seed attachment and is more difficult to gin than Pima and thus, usually has more carryover (Bechere et al., 2011).

As mentioned earlier, when reclaimers are heavily loaded with carryover/seed, a performance concern is that either residual carryover will pass through the reclaimer with the seed output and the attached lint will be lost, or residual seed will be returned to the gin stand with the reclaimed output and will be removed with trash at the gin-stand feeder and lost. Figure 13 shows the results of fractionating the seed output from the reclaimers into their components (seed and residual carryover) for Pima cotton. The conventional reclaimer had more seed and more residual carryover in the seed output than the 3 saw and 700 reclaimers. The conventional reclaimer allowed more residual carryover to pass through with the seed output, which is a loss. This carryover loss is a typical complaint with the conventional reclaimer. Also, figure 13 shows that the amount of seed that passed through the reclaimers in the seed output increased as the speed of the reclaimers was increased. This is also true for carryover in the 700 reclaimer where more residual carryover passed through with seed output at higher speeds. The amount of residual carryover that passed through the 3 saw was mostly unchanged by speed.

The results of fractionating the reclaimed output from Pima cotton into its components (carryover and residual 


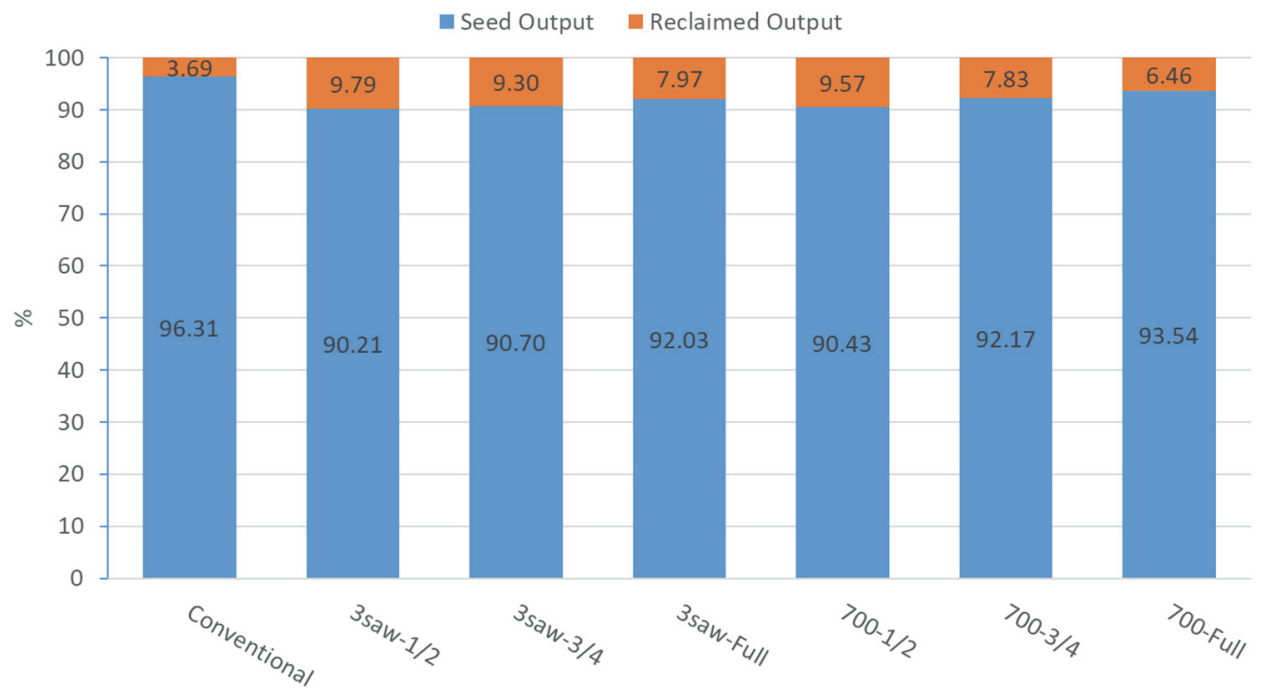

Figure 11. Proportions of Pima cotton carryover/seed separated into seed output and reclaimed output by the reclaimer treatments.

seed) showed that the conventional reclaimer had less carryover and less residual seed in the reclaimed output portion than the 3 saw and 700 reclaimers (fig. 14). The experimental reclaimers captured much more residual seed with the carryover that would be returned to the gin-stand feeder and likely lost with the feeder trash. Figure 14 shows that the amount of residual seed that is captured with the carryover in the reclaimed output decreased as the speed of the reclaimers was increased. This would make sense in that the seed would more easily sling-off of the reclaimer saws at higher speeds and likely not to stay attached to the saw with the carryover. This trend was also true for carryover in the 700 reclaimer, less carryover was reclaimed at higher speeds, likely for the same reason that it was slung-off with the seed at higher speeds. The results from the 3 saw reclaimer followed a different trend, suggesting that $3 / 4$ speed resulted in more reclaimed carryover than $1 / 2$ or full speed.

The results of fractionating the Upland seed output and reclaimed output from the reclaimers showed similar trends to those found with Pima. For the Upland cotton, the conventional reclaimer had more residual carryover in the seed output than the 3saw and 700 reclaimers, but the amount of seed was about the same as the experiment reclaimers (fig. 15). Figure 15 also shows that as the reclaimer speed increased the amount of seed and residual carryover that passed through reclaimer increased. The trends shown in figure 16 for the reclaimed output are opposite those for the seed portion. The conventional reclaimer reclaimed much less carryover than the 3 saw and 700 reclaimers. Also, residual seed was higher for the 3 saw and slowest speed 700 treatments than for the conventional. The amount of carryover and residual seed that were reclaimed by the 3saw and 700 reclaimers both decreased with increasing speed. Similar to the Pima cotton, the trend of more material passing through as seed output and less material in reclaimed output was likely due to increased sling-off action from the reclaimer saws at higher speeds.

Table 3 shows that when processing Pima cotton, the losses of residual carryover in the seed output for the conventional reclaimer were indeed significantly larger (p-value $<0.0001$ ) than the 3 saw and 700 reclaimers. In fact, the conventional reclaimer had $0.575 \mathrm{~kg}$ of lost carryover or

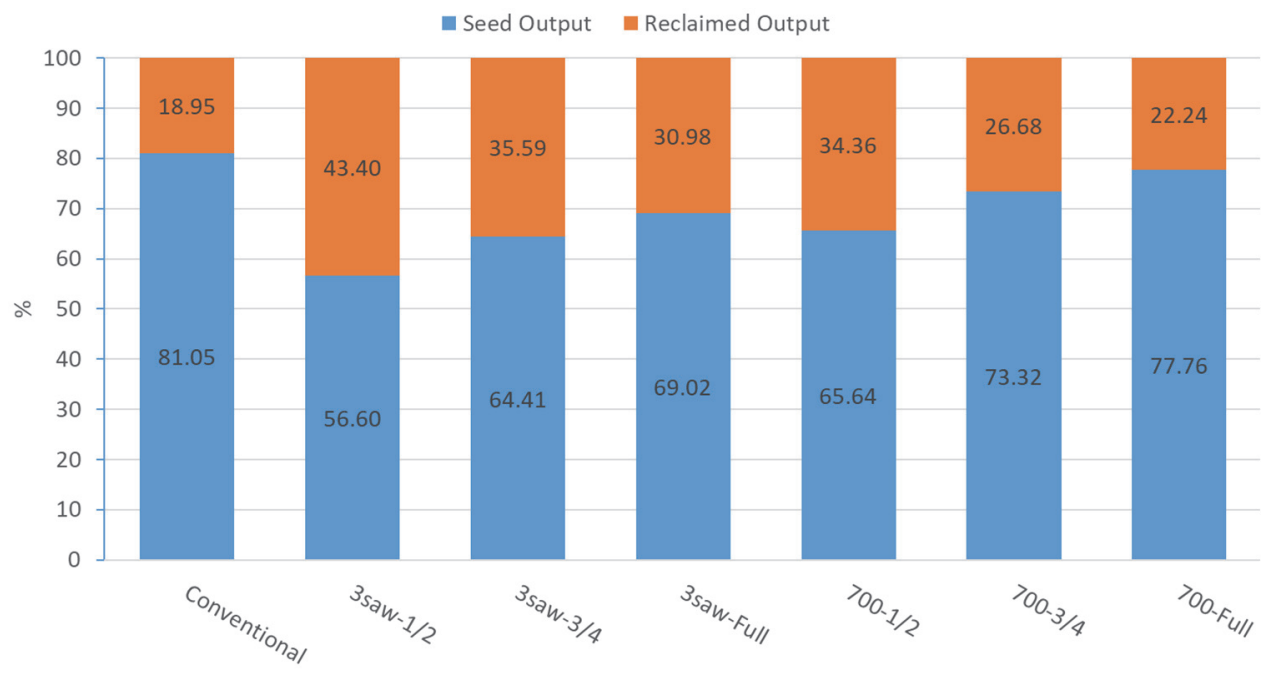

Figure 12. Proportions of Upland cotton carryover/seed separated into seed output and reclaimed output by the reclaimer treatments. 


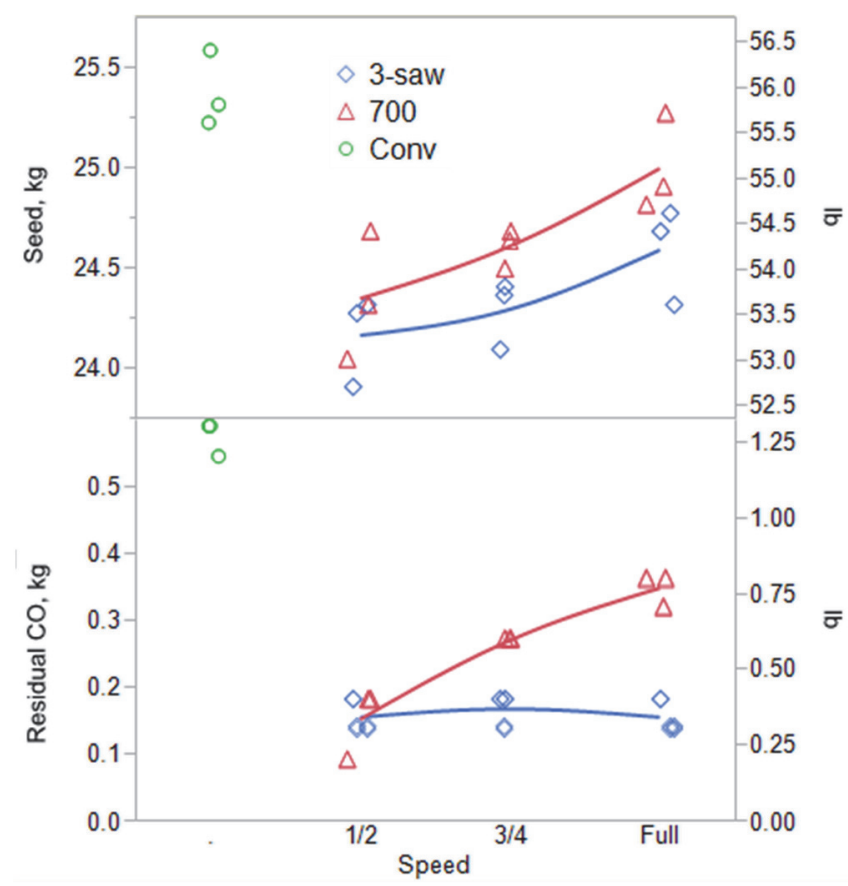

Figure 13. Seed and residual carryover (CO) in the seed output from the reclaimer treatments for the Pima cotton.

more than 1.5 times the loss of the closest experimental machine (700-Full with $0.347 \mathrm{~kg}$ lost carryover). The $3 \mathrm{saw}$ treatments' carryover losses averaged $0.158 \mathrm{~kg}(0.344 \mathrm{lb})$ and were smaller and significantly different from all other treatments, except the 700-1/2. Table 3 includes means of the amount of lint attached to the residual carryover in the seed. The experimental reclaimer treatment with the most lint loss (700-Full with $21.87 \mathrm{~g}$ of lint) had less than half that of the conventional reclaimer $(52.77 \mathrm{~g})$. The 3 saw treatments

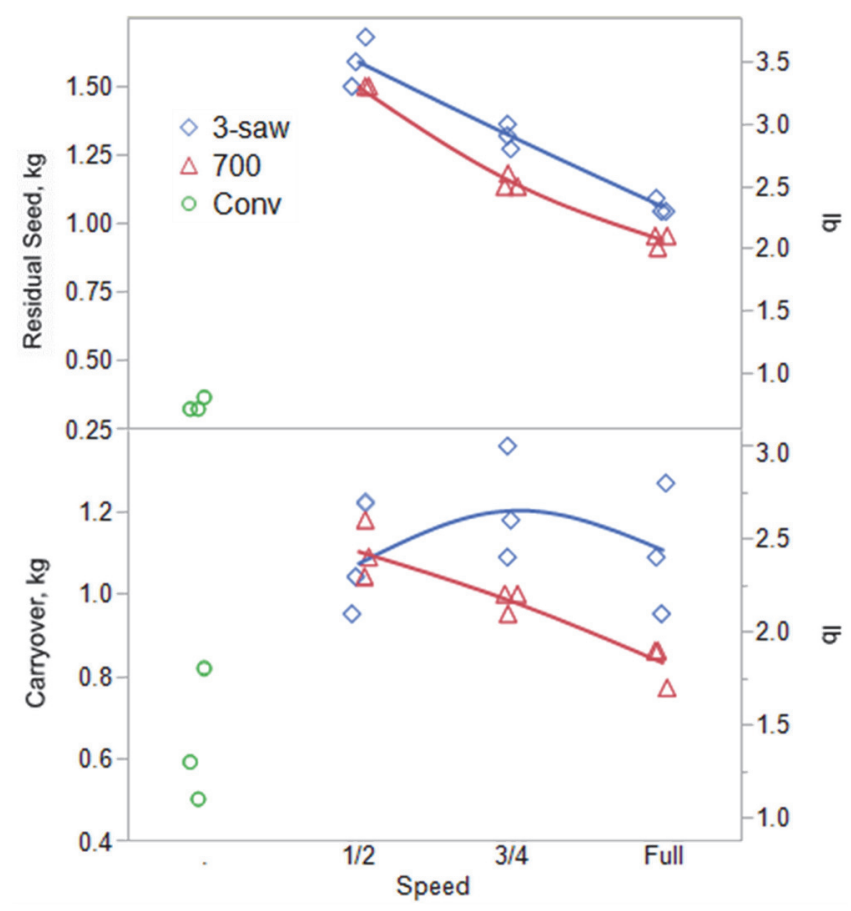

Figure 14. Carryover and residual seed in the reclaimed output from the reclaimer treatments for the Pima cotton.

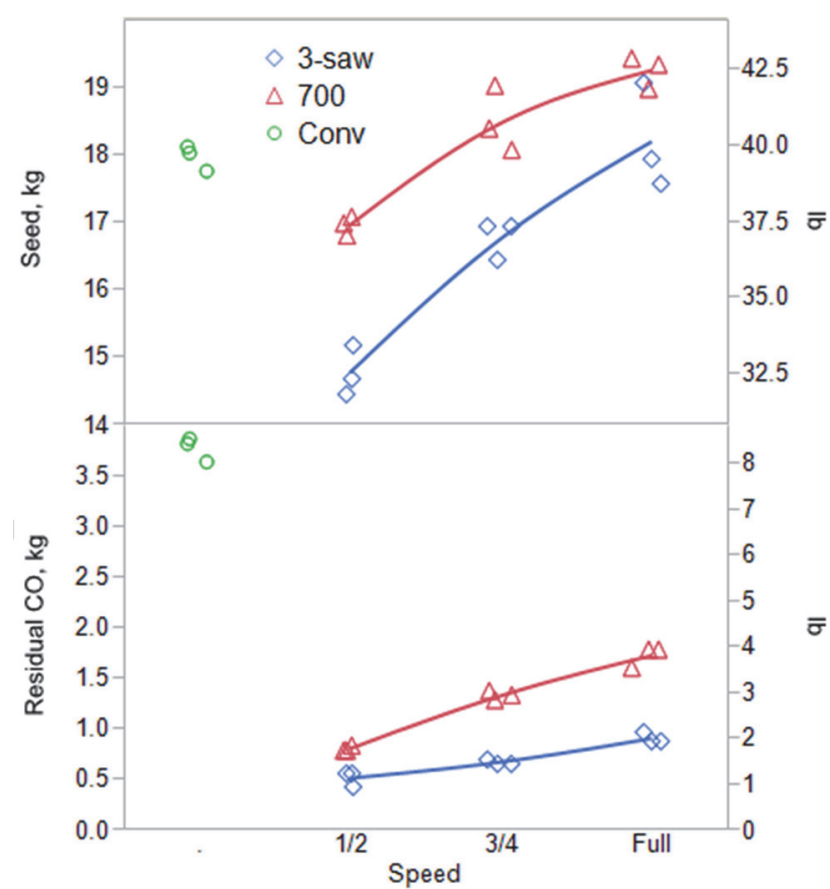

Figure 15. Seed and residual carryover $(\mathrm{CO})$ in the seed output from the reclaimer treatments for the Upland cotton.

had only about $10 \mathrm{~g}$ of lint attached. The value of this loss of lint assuming it would have otherwise been in the bale ranged from about $40 \notin$ per bale for the 3 saw treatments to $\$ 2.18$ per bale for the conventional. The results for residual seed in the reclaimed output are also shown in table 3 . The 3 saw-1/2 and 700-1/2 treatments had the most residual seed in the reclaimed output [ 1.59 and $1.50 \mathrm{~kg}$ (3.50 and $3.30 \mathrm{lb})$, respectively]. Among the experimental reclaimer treatments, the faster-speed treatments had less residual seed in the reclaimed output, the 700 -Full with the least $(0.937 \mathrm{~kg}$ [2.07 lb]). Overall, the conventional reclaimer had the least residual seed in the reclaimed output $(0.333 \mathrm{~kg}[0.733 \mathrm{lb}])$. Assuming that the residual seed in reclaimed output would be removed as trash at the gin-stand feeder, the value of the loss of residual seed in reclaimed output on a per bale basis ranged from a low of $\$ 1.38$ per bale for the conventional up to $\$ 6.60$ for the 3 saw-1/2 treatment. The total value of the combined Pima cotton lint and seed losses was highest for the slowest speed experimental reclaimer treatments $(\$ 7.02$ and $\$ 6.64$ for 3 saw-1/2 and 700-1/2, respectively) and was significantly different from the other treatments. The two fastest speed treatments (3saw-Full and 700-Full) had the lowest total loss of the experimental reclaimer treatments and the conventional had the lowest overall at $\$ 3.56$ per bale.

Table 4 shows that the results from processing Upland cotton follow similar trends to the results for Pima cotton. The residual carryover in the seed output for the 3 saw treatments and 700-1/2 treatment were less than $1 \mathrm{~kg}$ and were significantly different from the other 700 treatments and the conventional reclaimer. The $700-F u l l$ treatment had the most residual carryover in the seed output $[1.71 \mathrm{~kg}(3.77 \mathrm{lb})]$ of the experimental treatments, but still had less than half that of the conventional reclaimer $[3.77 \mathrm{~kg}(8.30 \mathrm{lb})]$. The residual carryover in the seed output for the conventional reclaimer were significantly more than the 3 saw and 700 


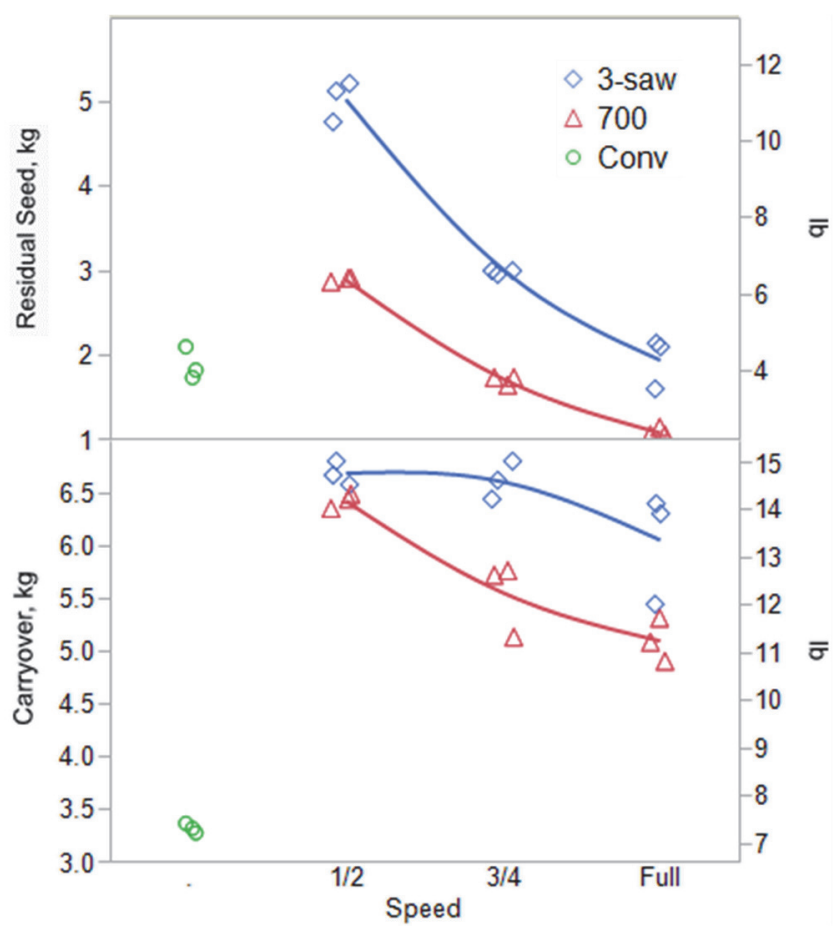

Figure 16. Carryover and residual seed in the reclaimed output from the reclaimer treatments for the Upland cotton.

reclaimers. The amount of lint left attached to the residual carryover in the seed output ranged from $31.97 \mathrm{~g}(0.0705 \mathrm{lb})$ for the $3 \mathrm{saw}-1 / 2$ treatment to $432.63 \mathrm{~g}(0.954 \mathrm{lb})$ for the conventional reclaimer. Among the experimental reclaimer treatments, the lint on the residual carryover for only the two slowest 3saw and slowest 700 treatments was different from that for the 700-Full treatment. The residual carryover in the seed output from the conventional reclaimer had almost 4 times more lint attached than the 700-Full treatment, un- derscoring the problem with the conventional reclaimer losing lint to the seed storage. The value of this lint lost with the seed was less than one-dollar per bale for the $1 / 2$ and $3 / 4$ speed 3 saw and $1 / 2$ speed 700 treatments. That value rose to $\$ 2.29$ per bale for the 700 -Full and was $\$ 8.67$ per bale for the conventional reclaimer. The residual seed in the reclaimed carryover from the $3 \mathrm{saw}-1 / 2$ treatment $[5.04 \mathrm{~kg}$ $(11.10 \mathrm{lb})$ ] was more than 1.5 times that of the next closest treatments (3saw-3/4 and 700-1/2). Like the results from Pima cotton, the faster-speed treatments had less residual seed in the reclaimed output. Different from the Pima cotton results, the fastest 700 reclaimer treatment had less residual seed in the reclaimed output $(1.07 \mathrm{~kg}$ [2.37]) than the conventional reclaimer $(1.87 \mathrm{~kg}$ [4.13 lb]). The value of this seed loss on a per bale basis was highest for the 3saw-1/2 (\$21.60 per bale) and lowest for the 700-Full (\$4.61 per bale). The seed loss value for the conventional reclaimer ( $\$ 8.04$ per bale) was between those two treatments and statistically not different from the 3saw-Full and 700-3/4 reclaimers. The total value of the losses (lint and seed combined) was highest for the slowest speed 3saw treatment (\$22.24 per bale) and was significantly different from the other treatments. This treatment had one of the lowest lint losses ( $\$ 0.64$ per bale), but the scale of its seed loss $(\$ 21.60)$ accounted for the majority (97\%) of its total loss. The conventional reclaimer had the second highest total loss (\$16.72), its lost lint value was highest and seed value was in the midrange. Overall, the 700 at full speed had the lowest total cost of $\$ 6.89$ per bale, its much lower seed value than the other treatments being the dominant factor.

There were several observations that held for both the Pima and the Upland cottons. The conventional reclaimer allowed more residual carryover to pass through with seed output, the attached lint lost to the seed storage. The experimental reclaimers were better at reclaiming carryover

Table 3. Treatment means and statistical analysis ${ }^{[a]}$ of reclaimer losses for Pima cotton: residual carryover in seed output (CO/SO), lint from residual carryover in the seed output (Lint/SO), residual ginned seed in the reclaimed output (Seed/RO), and value of losses.

\begin{tabular}{|c|c|c|c|c|c|c|c|c|c|c|c|c|c|c|c|}
\hline \multirow[b]{2}{*}{ Treatment } & \multicolumn{3}{|c|}{$\mathrm{CO} / \mathrm{SO}$} & \multicolumn{3}{|c|}{ Lint/SO } & \multirow{2}{*}{\multicolumn{2}{|c|}{$\begin{array}{l}\text { Lint Value } \\
\text { \$bale }\end{array}$}} & \multicolumn{3}{|c|}{ Seed/RO } & \multirow{2}{*}{\multicolumn{2}{|c|}{$\begin{array}{l}\text { Seed Value } \\
\$ \text { \$bale }\end{array}$}} & \multirow{2}{*}{\multicolumn{2}{|c|}{$\begin{array}{l}\text { Total Value } \\
\text { \$bale }\end{array}$}} \\
\hline & $\mathrm{kg}$ & $\mathrm{lb}$ & & $\mathrm{g}$ & $\mathrm{lb}$ & & & & $\mathrm{kg}$ & $\mathrm{lb}$ & & & & & \\
\hline Conventional & 0.575 & 1.27 & $\mathrm{a}$ & 52.77 & 0.116 & $\mathrm{a}$ & 2.18 & $\mathrm{a}$ & 0.333 & 0.733 & $\mathrm{e}$ & 1.38 & $\mathrm{e}$ & 3.56 & $\mathrm{~d}$ \\
\hline 3 saw-1/2 & 0.153 & 0.333 & $\mathrm{c}$ & 10.10 & 0.0223 & $\mathrm{~cd}$ & 0.417 & $\mathrm{~cd}$ & 1.59 & 3.50 & $\mathrm{a}$ & 6.60 & $\mathrm{a}$ & 7.02 & $\mathrm{a}$ \\
\hline 3 saw-3/4 & 0.167 & 0.367 & $\mathrm{c}$ & 8.93 & 0.0197 & $\mathrm{~d}$ & 0.367 & $\mathrm{~d}$ & 1.32 & 2.90 & $\mathrm{~b}$ & 5.47 & $\mathrm{~b}$ & 5.84 & $\mathrm{~b}$ \\
\hline 3saw-Full & 0.153 & 0.333 & $\mathrm{c}$ & 10.17 & 0.0224 & $\mathrm{~cd}$ & 0.423 & $\mathrm{~cd}$ & 1.06 & 2.33 & $\mathrm{c}$ & 4.40 & $\mathrm{c}$ & 4.82 & $\mathrm{c}$ \\
\hline $700-1 / 2$ & 0.150 & 0.333 & $\mathrm{c}$ & 10.20 & 0.0225 & $\mathrm{~cd}$ & 0.420 & $\mathrm{~cd}$ & 1.50 & 3.30 & $\mathrm{a}$ & 6.22 & $\mathrm{a}$ & 6.64 & $\mathrm{a}$ \\
\hline $700-3 / 4$ & 0.270 & 0.600 & $\mathrm{~b}$ & 16.17 & 0.0356 & bc & 0.667 & bc & 1.15 & 2.53 & $\mathrm{c}$ & 4.77 & $\mathrm{c}$ & 5.45 & $\mathrm{~b}$ \\
\hline 700-Full & 0.347 & 0.767 & $\mathrm{~b}$ & 21.87 & 0.0482 & $\mathrm{~b}$ & 0.903 & $\mathrm{~b}$ & 0.937 & 2.07 & d & 3.90 & $\mathrm{~d}$ & 4.80 & $\mathrm{c}$ \\
\hline p-value & \multicolumn{3}{|c|}{$<0.0001$} & \multicolumn{3}{|c|}{$<0.0001$} & \multicolumn{2}{|c|}{$<0.0001$} & \multicolumn{3}{|c|}{$<0.0001$} & \multicolumn{2}{|c|}{$<0.0001$} & \multicolumn{2}{|c|}{$<0.0001$} \\
\hline
\end{tabular}

[a] Means followed by the same letter in each column are not different based on Tukey HSD (p-value $\leq 0.05$ ).

Table 4. Treatment means and statistical analysis ${ }^{[a]}$ of reclaimer losses for Upland cotton: residual carryover in seed output (CO/SO), lint from residual carryover remaining in the seed output (Lint/SO), residual ginned seed in the reclaimed output (Seed/RO), and value of losses.

\begin{tabular}{|c|c|c|c|c|c|c|c|c|c|c|c|c|c|c|}
\hline \multirow[b]{2}{*}{ Treatment } & \multicolumn{2}{|c|}{$\mathrm{CO} / \mathrm{SO}$} & \multicolumn{3}{|c|}{ Lint/SO } & \multirow{2}{*}{\multicolumn{2}{|c|}{$\begin{array}{l}\text { Lint Value } \\
\text { \$ bale }\end{array}$}} & \multicolumn{3}{|c|}{ Seed/RO } & \multirow{2}{*}{\multicolumn{2}{|c|}{$\begin{array}{l}\text { Seed Value } \\
\$ / \text { bale }\end{array}$}} & \multirow{2}{*}{\multicolumn{2}{|c|}{$\begin{array}{l}\text { Total Value } \\
\text { \$/bale }\end{array}$}} \\
\hline & $\mathrm{kg}$ & $\mathrm{lb}$ & $\mathrm{g}$ & $1 \mathrm{~b}$ & & & & $\mathrm{~kg}$ & $\mathrm{lb}$ & & & & & \\
\hline Conventional & 3.77 & $8.30 \quad \mathrm{a}$ & 432.63 & 0.954 & $\mathrm{a}$ & 8.67 & $\mathrm{a}$ & 1.87 & 4.13 & $\mathrm{c}$ & 8.04 & $\mathrm{c}$ & 16.72 & $\mathrm{~b}$ \\
\hline 3 saw- $1 / 2$ & 0.497 & $1.10 \mathrm{f}$ & 31.97 & 0.0705 & $\mathrm{c}$ & 0.643 & $\mathrm{c}$ & 5.04 & 11.10 & $\mathrm{a}$ & 21.60 & $\mathrm{a}$ & 22.24 & $\mathrm{a}$ \\
\hline 3saw-3/4 & 0.653 & 1.43 ef & 35.53 & 0.0783 & $\mathrm{c}$ & 0.710 & c & 2.98 & 6.57 & $\mathrm{~b}$ & 12.78 & $\mathrm{~b}$ & 13.49 & c \\
\hline 3saw-Full & 0.890 & $1.97 \mathrm{~d}$ & 71.00 & 0.157 & $\mathrm{bc}$ & 1.42 & bc & 1.94 & 4.27 & $\mathrm{c}$ & 8.30 & $\mathrm{c}$ & 9.73 & d \\
\hline $700-1 / 2$ & 0.787 & $1.73 \mathrm{de}$ & 44.80 & 0.0988 & $\mathrm{c}$ & 0.900 & $\mathrm{c}$ & 2.89 & 6.37 & $\mathrm{~b}$ & 12.39 & $\mathrm{~b}$ & 13.29 & $\mathrm{c}$ \\
\hline $700-3 / 4$ & 1.32 & $2.90 \mathrm{c}$ & 87.10 & 0.192 & $\mathrm{bc}$ & 1.74 & $\mathrm{bc}$ & 1.69 & 3.73 & c & 7.27 & $\mathrm{c}$ & 9.01 & $\mathrm{~d}$ \\
\hline 700-Full & 1.71 & $3.77 \mathrm{~b}$ & 114.20 & 0.252 & $\mathrm{~b}$ & 2.29 & $\mathrm{~b}$ & 1.07 & 2.37 & $\mathrm{~d}$ & 4.61 & $\mathrm{~d}$ & 6.89 & $\mathrm{e}$ \\
\hline p-value & \multicolumn{2}{|c|}{$<0.0001$} & \multicolumn{3}{|c|}{$<0.0001$} & \multicolumn{2}{|c|}{$<0.0001$} & \multicolumn{3}{|c|}{$<0.0001$} & \multicolumn{2}{|c|}{$<0.0001$} & \multicolumn{2}{|c|}{$<0.0001$} \\
\hline
\end{tabular}

[a] Means followed by the same letter in each column are not different based on Tukey HSD $(\mathrm{P} \leq 0.05)$. 
from the carryover/seed, especially at slower speeds. However, the slower speed experimental reclaimers captured more seed with the reclaimed output that would be returned to the gin-stand feeder and lost with the feeder trash. This was likely due to seed with some residual fibers attached clinging to the reclaimer saws at slower speeds as opposed to that seed being more easily slung-off the saws due to greater centrifugal force at higher speeds. This effect would be greater for the fuzzy Upland seed than the naked Pima seed. Because Pima cotton is more easily ginned on the roller gin than Upland cotton and thus, has less carryover removed from the ginning point by the rotary knife, there were discernable differences in the performance of the reclaimers between the two cottons. For Pima, less carryover in the carryover/seed meant that the tendency of the conventional reclaimer to allow residual carryover to pass through with the seed output had less impact on its combined value of seed and lint loss, resulting in the conventional reclaimer having the least total loss for Pima cotton. For Upland cotton with much more carryover in the carryover/seed, the impact of the carryover loss by the conventional reclaimer made its performance less desirable than most of the experimental treatments even with lower residual seed loss in the reclaimed seed cotton.

\section{CONCLUSION}

Tests were conducted to evaluate two experimental highcapacity roller-gin reclaimers and compare their performance to a conventional reclaimer. The experimental reclaimers were a modified 3-saw cylinder stick machine and a Lummus 700 III gin-stand feeder with saw-cylinder operating speeds ranging from $1 / 2$ to full speed. An ideal reclaimer would reclaim carryover (partially or unginned seed cotton) from the carryover and seed mixture removed from the ginning point by the rotary knife, while minimizing the amount of residual seed that is also reclaimed (seed loss), and allow ginned seed to pass, while minimizing the amount of residual carryover with lint attached that passes through with the seed to the seed storage (lint loss). The test results showed that the experimental reclaimers reclaimed more carryover from the carryover/seed than the conventional reclaimer and minimized the residual carryover in the seed output, but captured more residual ginned seed with the reclaimed output (seed loss). On the other hand, the conventional reclaimer had less residual seed loss with the reclaimed output than the experimental reclaimers, but allowed more residual carryover with attached lint to pass through with the seed (lint loss). Increasing the saw-cylinder speeds of the experimental reclaimers decreased the seed loss, but increased the lint loss. Calculation of the total combined value of the seed lost and of the lint lost that was attached to the lost carryover revealed that the conventional reclaimer had the lowest total loss of $\$ 3.56$ per bale when processing Pima cotton. The 700 feeder with saw-cylinders operating at full speed had the lowest total loss of $\$ 6.89$ per bale when processing Upland cotton.

\section{FUTURE WORK}

Since the conventional reclaimer had greater losses of residual carryover with the seed output, and the experimental reclaimers had greater losses of residual seed with the reclaimed output, it may be beneficial to use some combination in series of different types of reclaimers to take advantage of each of their respective best features. The performance of the reclaimer machines used in series may be estimated based on the data from this test of single machines, particularly the portion of the carryover/seed fed to the reclaimers that was reclaimed output and the residual seed in that reclaimed output, and the portion of carryover/seed that passed through as seed output and the residual carryover in that seed output. A number of potential series combinations with the lowest estimated losses of seed and lint may be evaluated for increased overall performance with high-speed roller ginning.

\section{REFERENCES}

Anthony, W. S., \& McCaskill, O. L. (1974). Development and evaluation of a small-scale cotton ginning system. Report S-36. Washington, DC: USDA-ARS.

Armijo, C. B., \& Gillum, M. N. (2007). High-speed roller ginning of upland cotton. Appl. Eng. Agric., 23(2), 137-143. https://doi.org/10.13031/2013.22603

Armijo, C. B., \& Gillum, M. N. (2010). Conventional and high-speed roller ginning of upland cotton in commercial gins. Appl. Eng. Agric., 26(1), 5-10. https://doi.org/10.13031/2013.29465

Armijo, C. B., Foulk, J. A., Whitelock, D. P., Hughs, S. E., Holt, G. A., \& Gillum, M. N. (2013). Fiber and yarn properties from highspeed roller ginning of upland cotton. Appl. Eng. Agric., 29(4), 461-471. https://doi.org/http://dx.doi.org/10.13031/aea.29.9955

Armijo, C. B., Whitelock, D. P., Thomas, J. W., Hughs, S. E., \& Gillum, M. N. (2017). Roller ginning. J. Cotton Sci., 21(3), 199209.

Baker, R. V., Anthony, W. S., \& Sutton, R. M. (1994). Seed cotton cleaning and extracting. In Cotton ginners handbook. Agricultural handbook No. 503. Washington, DC: USDA-ARS.

Bechere, E., Boykin, J. C., \& Meredith, W. R. (2011). Evaluation of cotton genotypes for ginning energy and ginning rate. J. Cotton Sci., 15(1), 11-21.

Funk, P. A., Terrazas, A. A., Yeater, K. M., Hardin, R. G., Armijo, C. B., Whitelock, D. P.,... Delhom, C. D. (2018). Procedures for moisture analytical tests used in cotton ginning research. Trans. ASABE, 61(6), 1985-1995. https://doi.org/10.13031/trans.12980

Gillum, M. N. (1979). USDA Southwestern Cotton Ginning Research Laboratory annual report: Crop years 1978-1979. 220239. Washington, DC: USDA.

Hughs, S. E. (2009). Development of a seed cotton reclaimer for roller gins. Proc. Beltwide Cotton Conf., (p. 614). Cordova, TN: Natl. Cotton Council America.

Hughs, S. E., Thomas, J. W., Armijo, C. B., \& Delhom, C. D. (2015). New seed-cotton reclaimer for high speed roller gins. Proc. Beltwide Cotton Conf., (p. 969). Cordova, TN: Natl. Cotton Council America.

Informa Economics. (2013). Cotton intelligence monthly. 17(8), 1-4. Informa Economics. Retrieved from www.cottoninc.com/wpcontent/uploads/2017/02/CIM08_2013.pdf

Informa Economics. (2014). Cotton intelligence monthly. 18(9), 1-4. Informa Economics. Retrieved from www.cottoninc.com/wpcontent/uploads/2017/02/CIM09_2014.pdf 
Informa Economics. (2015). Cotton intelligence monthly. 19(9), 1-4. Informa Economics. Retrieved from www.cottoninc.com/wpcontent/uploads/2017/02/CIM09_2015.pdf

Informa Economics. (2016). Cotton intelligence monthly. 20(9), 1-4. Informa Economics. Retrieved from www.cottoninc.com/wpcontent/uploads/2017/02/CIM09_2016.pdf

Informa Economics. (2017). Cotton intelligence monthly. 21(10), 14. Informa Economics. Retrieved from www.cottoninc.com/wpcontent/uploads/2018/02/CIM10_2017.pdf
Shepherd, J. V. (1972). Standard procedures for foreign matter and moisture analytical tests used in cotton ginning research. Stock No. 0100-1509. Washington, DC: U.S. Government Printing Office.

USDA-ERS. (2018). Cotton and wool yearbook. Washington, DC: USDA-ERA. Retrieved from www.ers.usda.gov/dataproducts/cotton-wool-and-textile-data/cotton-and-woolyearbook/.

Whitelock, D. P., Armijo, C. B., Gamble, G. R., \& Hughs, S. E. (2007). Survey of seed-cotton and lint cleaning equipment in U.S. roller gins. J. Cotton Sci., 11, 128-140. 